\title{
Histological analysis of spermatogenesis and the germ cell seasonal development within the testis of domesticated tree shrews (Tupaia belangeri chinensis)
}

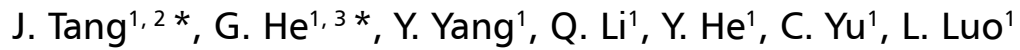 \\ ${ }^{1}$ School of Basic Medical Sciences, Kunming Medical University, Kunming, China \\ 2Department of Medical Genetics and Prenatal Diagnosis, Kunming Maternity and Child Health Hospital, Kunming, China \\ ${ }^{3}$ Clinical Laboratory, Yunnan Maternal and Child Health Care Hospital, Kunming, China
}

[Received: 1 March 2021; Accepted: 22 April 2021; Early publication date: 6 May 2021]

\begin{abstract}
Background: This study aimed to address the lack of information on the male germ cell seasonal development of domesticated tree shrews (Tupaia belangeri chinensis).

Materials and methods: Testicular tissues were collected from 60 tree shrews ( $n=5$ per month). The ultrastructures of the testes and spermatids were examined via transmission electron microscopy. Apoptosis of spermatogenic cells was measured through terminal deoxynucleotidyl transferase dUTP nick end labelling (TUNEL) staining. The expression of proliferation factors, namely, proliferating cell nuclear antigen (PCNA) and Ki67, in testicular tissues was assayed through immunohistochemistry.
\end{abstract}

Results: Spermatid ultrastructure showed seasonal differences, and spermatogenesis was relatively active in June and July and relatively stagnant from October to November. The percentage of TUNEL-positive germ cells was less during October and November, while greater in July than other phases. The number of PCNA-nucleus-positive germ cells was most in June and July, but with cytoplasm staining from October to November. Ki67 presented positive expression in the testes from April to September, with highest expression in June, but with no expression from October to March.

Conclusions: In summary, there are seasonal differences in tissue morphology related to spermatogenesis in domesticated tree shrews. PCNA expression and Ki67 expression are good indicators of seasonal differences in male germ cells. (Folia Morphol 2022; 81, 2: 412-420)

Key words: tree shrew, spermatogenic cell, seasonal differences, testis

\section{INTRODUCTION}

Tree shrews (Tupaia belangeri chinensis), which belong to the family Tupaiidae, genus Tupaia, are rat-sized mammals that live mainly in deciduous, evergreen and secondary forests in tropical and subtropical regions [30]. Whole-genome sequencing

Address for correspondence: Prof. L. Luo, No. 1168 Chunrong West Road, Yuhua Street, Chenggong, Kunming, China, tel +86 871-65922865, e-mail: luolan@kmmu.edu.cn

*Equal contribution

This article is available in open access under Creative Common Attribution-Non-Commercial-No Derivatives 4.0 International (CC BY-NC-ND 4.0) license, allowing to download articles and share them with others as long as they credit the authors and the publisher, but without permission to change them in any way or use them commercially. 
analysis has revealed that tree shrews are similar to humans with regard to histology, physiology, biochemistry, and nervous (brain function), metabolic and immune systems $[8,22,24]$. The tree shrew is small, has a short reproductive cycle, is easy to perform experiments on, is inexpensive to feed, and has other favourable characteristics, such as susceptibility to a wide range of human pathogenic viruses [32]. Thus, the tree shrew may be a good animal model for scientific experiments.

Studies have shown that the reproduction of sexually mature male wild tree shrews has obvious seasonality; the reproductive season lasts only from April to July each year [29]. In a previous study by Cao [4], highly active seminiferous epitheliums were observed in January and April. Regression of seminiferous tubules begins in July and there are extensive regressive changes in seminiferous epitheliums losing spermatogenic function in August and October. Similar seasonal changes in spermatozoa amount are shown in epididymis. However, recent studies have reported that artificial domestication can overcome the seasonal restrictions of tree shrew reproduction [14]. The seasonal reproduction pattern of this species has caused considerable uncertainty and unforeseen complications related to the reproducibility, stability and comparability of male reproductive medicine studies using the tree shrew as a model organism, which has restricted the use of the tree shrew as a model organism for reproduction research. However, there have been no studies on the seasonal differences in morphology or proliferation and apoptosis levels in domesticated tree shrew sperm.

Spermatogenesis is a complex process. Sperm matures through the mitosis of spermatogonia, meiosis of spermatocytes, and maturation of spermatids [9]. Spermatogenic cells proliferate often, develop continuously and have physiological significance in the process of spermatogenesis. Proliferating cell nuclear antigen (PCNA) is a cell cycle regulatory protein marker that is closely related to DNA synthesis and participates in the initiation of cell proliferation [26]. Ki67, another nuclear antigen related to cell proliferation, exists in the cell nucleus and participates in the mitotic prophase-to-metaphase transition and the maintenance of DNA structure $[13,23]$. Therefore, the protein expression levels of PCNA and Ki67 in the testes are standard markers for the proliferation of spermatogenic cells [31]. Additionally, apoptosis of spermatogenic cells in the testes may contribute to seasonal differences in sperm [3].
The present study aimed to investigate whether there are seasonal differences in spermatogenesis in domesticated tree shrews. We examined 1) spermatids morphology using haematoxylin and eosin (HE) staining and transmission electron microscopy (TEM); 2) the frequency of apoptosis using a terminal deoxynucleotidyl transferase dUTP nick end labelling (TUNEL) assay; and 3) immunohistochemical staining of PCNA or Ki67 in testis collected from tree shrews in different seasons.

\section{MATERIALS AND METHODS}

\section{Animals and treatment}

Sixty 18-month-old healthy tree shrews, weighing 128-151 g, were obtained from the Animal Centre of Kunming Medical University and kept in a standard animal house with a temperature of $25^{\circ} \mathrm{C}$ and a humidity of $45 \%$ at $12 \mathrm{L:12D}$ (lights on at 08:00). Five tree shrews were randomly selected for the experiment every month. The study was approved by the Ethics Committee of Kunming Medical University (Kunming, China, No. KM16/17), and the experimental animals comply with the guidelines of the Chinese Ethics Committee.

The tree shrews were anaesthetized with isoflurane, and the testicles were quickly taken. A tissue block of about $2 \mathrm{~mm}$ was cut from one of the testicles and fixed with $2.5 \%$ glutaraldehyde for TEM. The rest of the testicles were fixed overnight with $10 \%$ neutral formaldehyde within 2 min after sampling, dehydrated in alcohol series, transparent in xylene, and embedded in conventional paraffin. The slice thickness was $5 \mu \mathrm{m}$, and it was pasted on a glass slide pre-treated with Poly-L-Lysine, and the slice was baked at $60^{\circ} \mathrm{C}$ for $1 \mathrm{~h}$, and stored at $4^{\circ} \mathrm{C}$ for later experiments.

\section{Histomorphological examination}

Testicular sections were prepared as described above. The $5-\mu \mathrm{m}$ testicular sections were continuously sliced and stained with HE. The histological structure was then observed under a light microscope (Nikon 90i, Tokyo, Japan).

\section{Transmission electron microscopy}

The $2 \mathrm{~mm}$ thick gonadal sections were fixed in $2.5 \%$ glutaraldehyde in $0.1 \mathrm{M}$ phosphate buffer $\mathrm{pH}$ 7.4 for $3 \mathrm{~h}$ at $4^{\circ} \mathrm{C}$ and post fixed in $1 \%$ osmium tetroxide in $0.1 \mathrm{M}$ phosphate buffer overnight at room temperature. Samples were then dehydrated in $75 \%$, 
$85 \%, 95 \%$, and $100 \%$ alcohols and in $100 \%$ acetone, and then embedded in an epoxy Spurr resin. Ultrathin sections of $50 \mathrm{~nm}$ were cut and stained with lead citrate-uranyl acetate, then observed by TEM (JEM1000, JEOL, Tokyo, Japan).

\section{Immunohistochemistry assay}

The $5-\mu \mathrm{m}$ paraffin slices were baked $65^{\circ} \mathrm{C}$ for $30 \mathrm{~min}$, dewaxed, and rehydrated in xylene, alcohol and distilled water. Afterward, antigen retrieval was conducted in a microwave oven. Endogenous peroxidase activity in sections was quenched by $3 \%$ hydrogen peroxide at room temperature for $30 \mathrm{~min}$, and the sections were then blocked with $5 \%$ bovine serum for $15 \mathrm{~min}$. The sections were incubated with diluted primary antibody (PCNA, ab29, 1:100 dilutions; Ki67, ab15580, 1:100 dilutions, Abcam, MA, USA) overnight at $4^{\circ} \mathrm{C}$. Then, the section was immunohistochemistry (IHC) staining using MaxVision ${ }^{\mathrm{TM}}$ HRP-Polymer anti-Mouse/Rabbit IHC Kit (MXB Biotechnologies Inc., Fuzhou, China). The sections were counterstained with haematoxylin and rinsed in tap water. IHC micrographs were observed under a microscope (Nikon 90i). The PCNA and Ki67 protein nuclei show brown-yellow particles as a positive reaction.

\section{TUNEL assay}

The level of apoptosis-related DNA fragmentation in the testicular tissues was evaluated by TUNEL assay by using a commercially available kit (Roche, Indianapolis, IN, USA). The sections of $5-\mu \mathrm{m}$ paraffin tissue specimens were serially sectioned, and the standard method was applied according to the manufacturer's instructions. The sections were observed under a light microscope, and the cells in the testis exhibiting brown nuclear staining were considered positive for nuclear DNA fragmentation.

\section{Statistical analysis}

Statistical analyses were performed using GraphPad prism 6.0. Data were expressed as mean \pm standard deviation, and analysis of variance was done on non-parametric test. Student's t-test was performed for statistical analyses. $P<0.05$ was indicated statistical significance.

\section{RESULTS}

\section{Histological structures of the testes}

The histological changes in the testes are shown in Figure 1. In January, most of the seminiferous tubules could be observed at different developmental stages in testis tissue. Spermatogonia were attached to the basement membrane of seminiferous tubules, which was small size, lightly stained and with round nucleus. The primary spermatocytes was in the second and third layers, which was slender size, deeply stained, and with round nucleus. The secondary spermatocytes and round spermatids were near the centre of the lumen, these cells were smaller, lightly stained and with round nucleus. Some fully deformed or partly deformed spermatozoa and residues could be observed near the lumen. Deformed spermatozoa showed darker staining and had a superimposed fusiform shape, while the residue was lighter staining and of irregular shape (Fig. 1A). Compared with January, the number of deformed spermatozoa and its residue in the lumen of the thin tubules increased month by month from February to May (Fig. 1B-E). From June to July, spermatogonia, primary spermatocytes, secondary spermatocytes, round spermatids, a large number of deformed spermatozoa and its residue almost filled the lumen (Fig. 1F, G). From August to September, spermatogenic cells at different developmental stages were observed in the seminiferous tubules of testis tissue, but the number of deformed spermatozoa and its residue began to decrease month by month (Fig. $1 \mathrm{H}, \mathrm{I})$. In October, the arrangement of seminiferous tubules and spermatogenic cells in the testes became regular and compact and cavitation were present in part of the seminiferous tubules. Few deformed spermatozoa and its residue were observed (Fig. 1J). From November to December, the number of deformed spermatozoa and its residual increased compared with October, which was similar to the structure of seminiferous tubules in January (Fig. 1K, L).

\section{Ultrastructure of the testicular tissue and sperm of tree shrews}

The TEM images of the testicular tissue and spermatozoa ultrastructures are shown in Figure 2. In January, there were few free spermatozoa in the lumens of the seminiferous tubules. Some primary spermatocytes had shrunken nuclei, ruptured nuclear membranes, agglutination of organelles, and nearly round apoptotic bodies with enhanced electron density. A small number of primary spermatocytes presented putamen (Fig. 2F). Additionally, abnormal morphological features in sperm such as head mass loss, vacuolisation, and crooked tails were also observed (Fig. 2L, R). From February to July, the numbers 

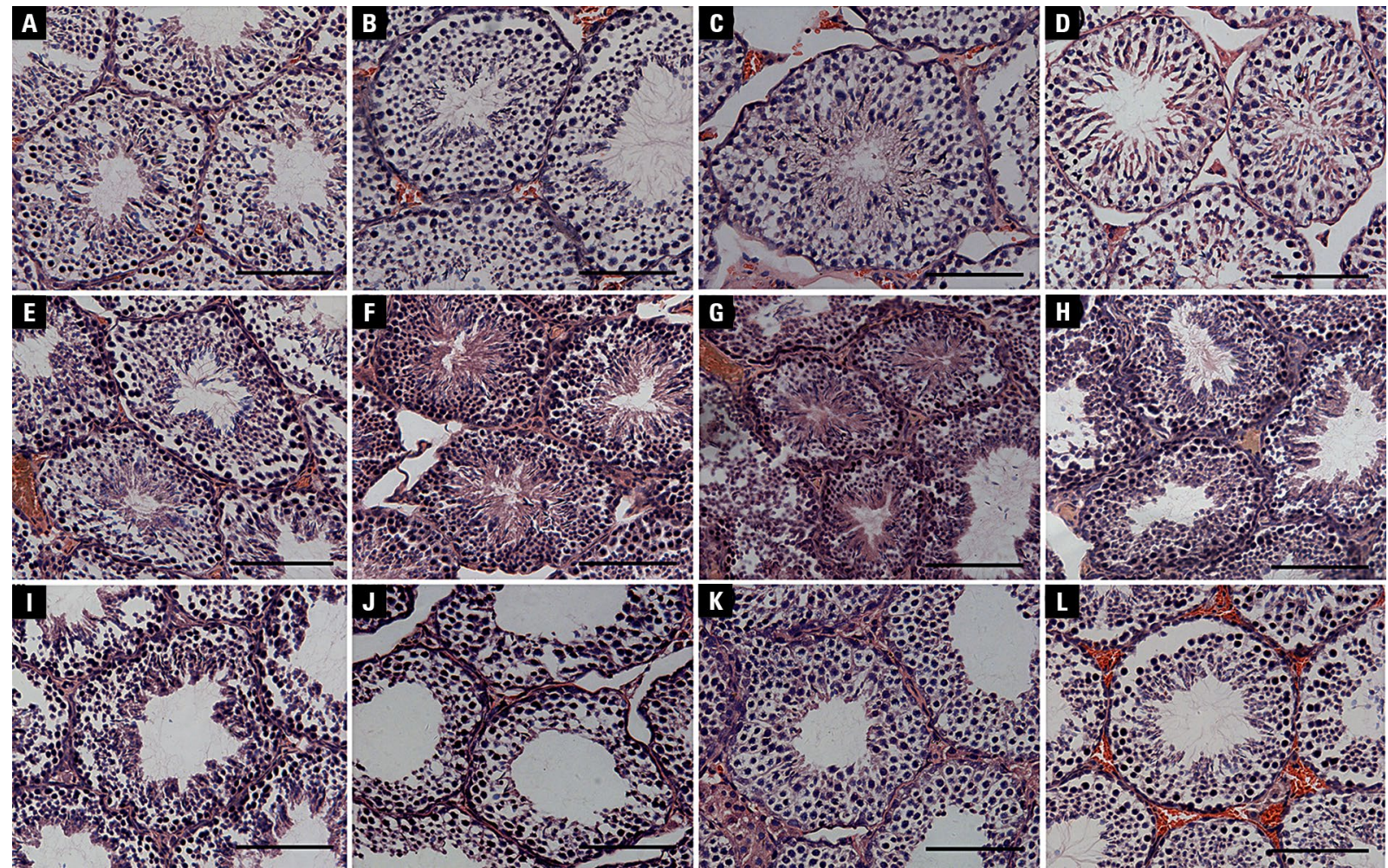

Figure 1. A-L. Morphological changes in the testis of the domesticated tree shrew. Haematoxylin-eosin staining of paraffin-embedded sections of testis from male tree shrew from January to December. Bar $=100 \mu \mathrm{m}$.

of free spermatozoa in the lumens of seminiferous tubules gradually increased (Fig. 2G-I), and the deformed spermatozoa and free spermatozoa gradually returned to their normal forms (Fig. 2M-O).

In August/September, the chromatin of some primary sperm cells in the seminiferous tubules shrank, and the nuclear membranes disappeared (Fig. 2P). The numbers of free spermatozoa in the lumens of seminiferous tubules were significantly lower in August than in July (Fig. 2J). From September to December, the chromosomes of spermatogonia or primary spermatocytes gradually shrank, and apoptotic bodies with enhanced electron density appeared (Fig. 2D, E). The number of free sperm gradually decreased. Abnormally shaped sperm gradually appeared, including sperm with missing heads, vacuolisation, etc. (Fig. 2J, K).

\section{IHC assay of PCNA and Ki67 expression in testicular tissues}

Proliferating cell nuclear antigen-positive cells were found mainly in spermatogonia and primary spermatocytes in convoluted tubules. In the testicular tissues collected from June and July, PCNA showed strong positive staining in the nucleus (Fig. 3A). In the testicular tissues collected from October and November, the expression of PCNA protein was observed in the cytoplasm instead of in the nucleus (Fig. 3B).

The Ki67 protein showed strong positive staining in spermatogonia and primary spermatocytes and weak positive staining in secondary spermatocytes and spermatids. In the testicular tissues collected from June and July, the cells with positive expression of the Ki67 protein were mainly spermatogonia, primary spermatocytes, and a small number of secondary spermatocytes (Fig. 3C). In the testicular tissues collected from October to March, Ki67-positive cells were not observed among any spermatogenic cells in the seminiferous tubules (Fig. 3D).

\section{TUNEL assay of the testicular tissue and spermatids of tree shrews}

As shown in Figure 4, testis sections were analysed using a TUNEL assay. Apoptosis of spermatogonia and primary spermatocytes was observed in the testicular tissue from January to September and December (Fig. $4 \mathrm{~A}-\mathrm{I}, \mathrm{L})$. The apoptosis rate was highest in July (Fig. 

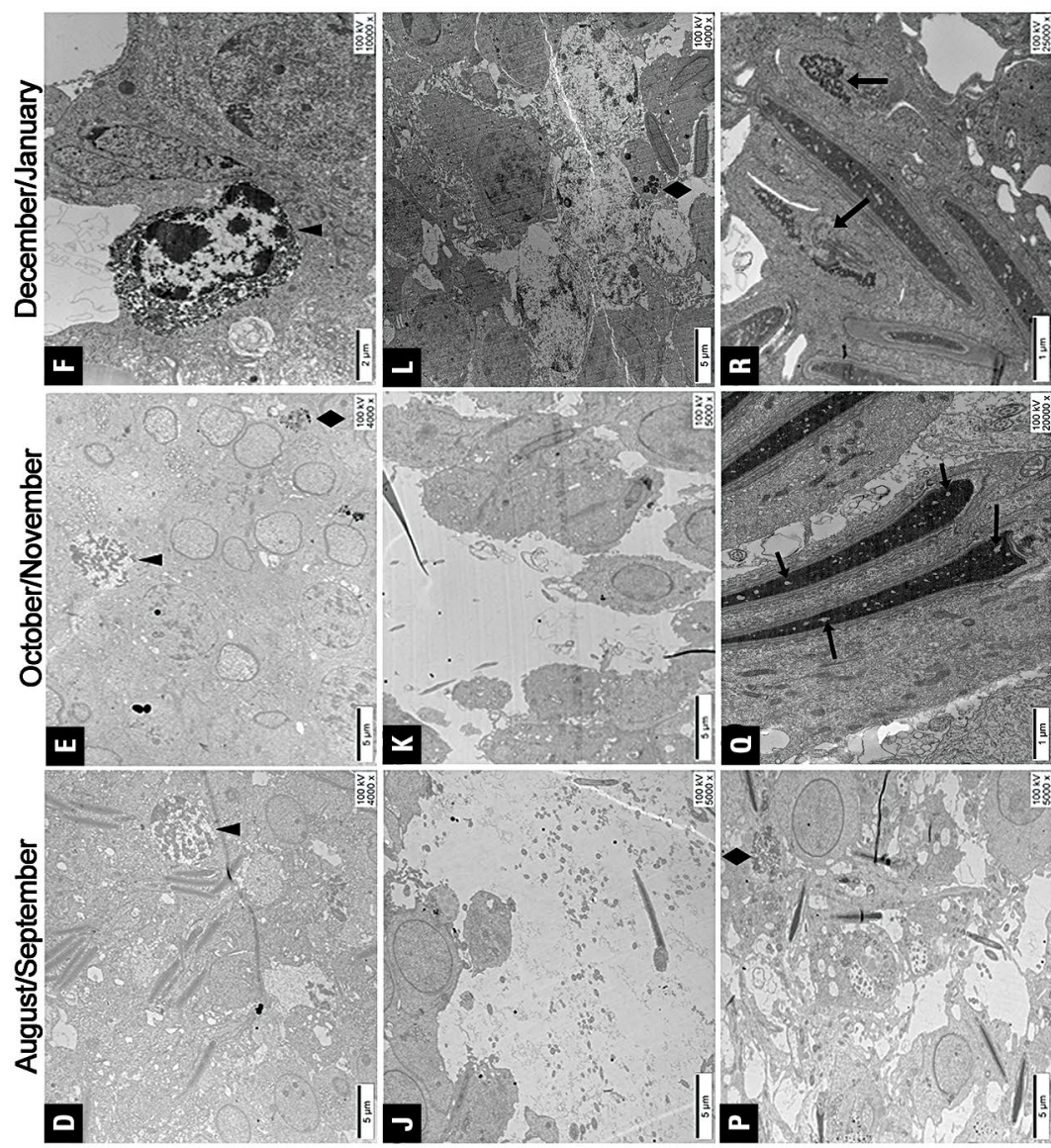

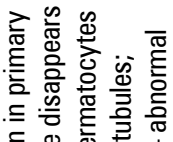

बे

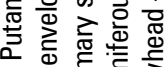

$<$ 就

을 음

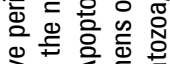

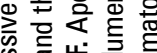

政

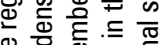

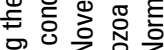

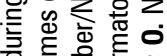

응 응 흥.

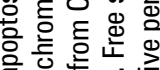

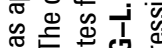

क्षे

空言竞

क के

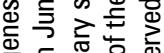

递

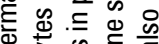

的

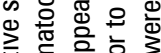

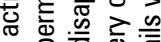

क्ष के क्ष

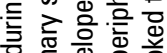

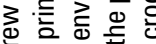

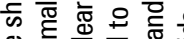

\&

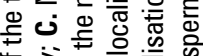

पํ.

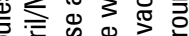

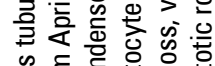

응 항 응 응

这类
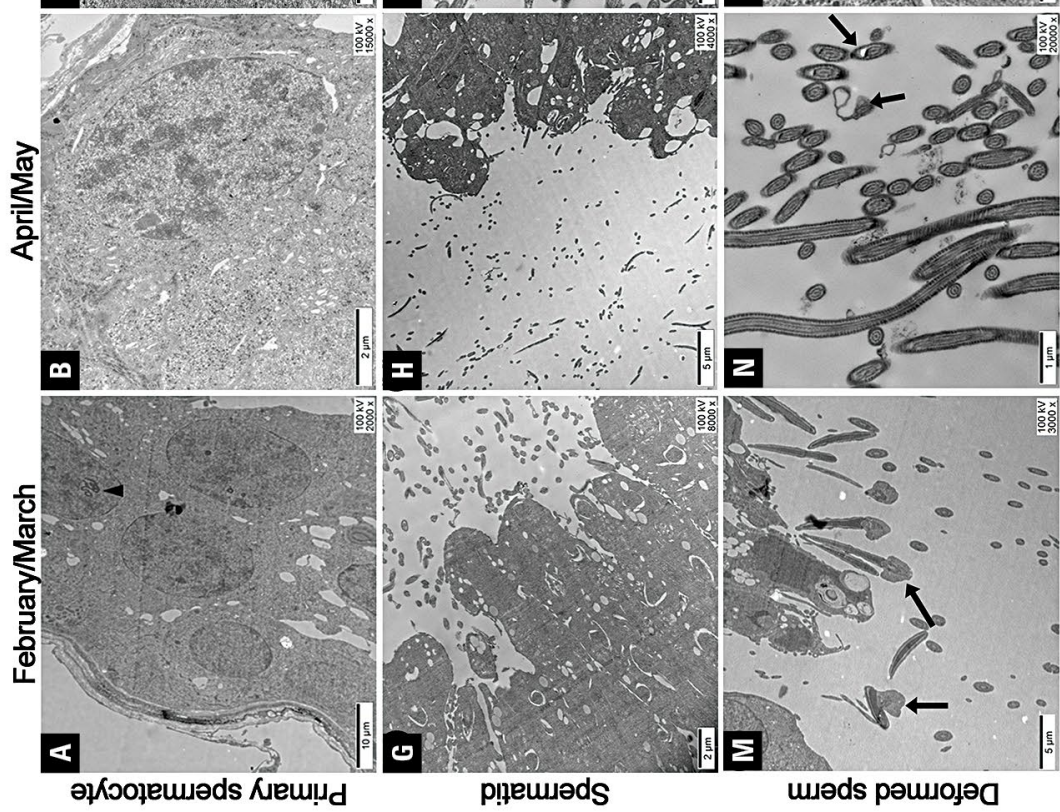

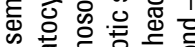
赵 해응 응 등 훟

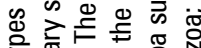
ن . 突 है 흘 है है के 인 흥등 क 品离

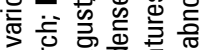

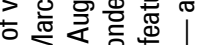

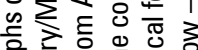

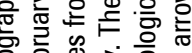

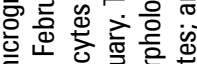

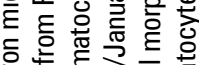
究 एँ 의

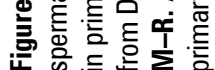



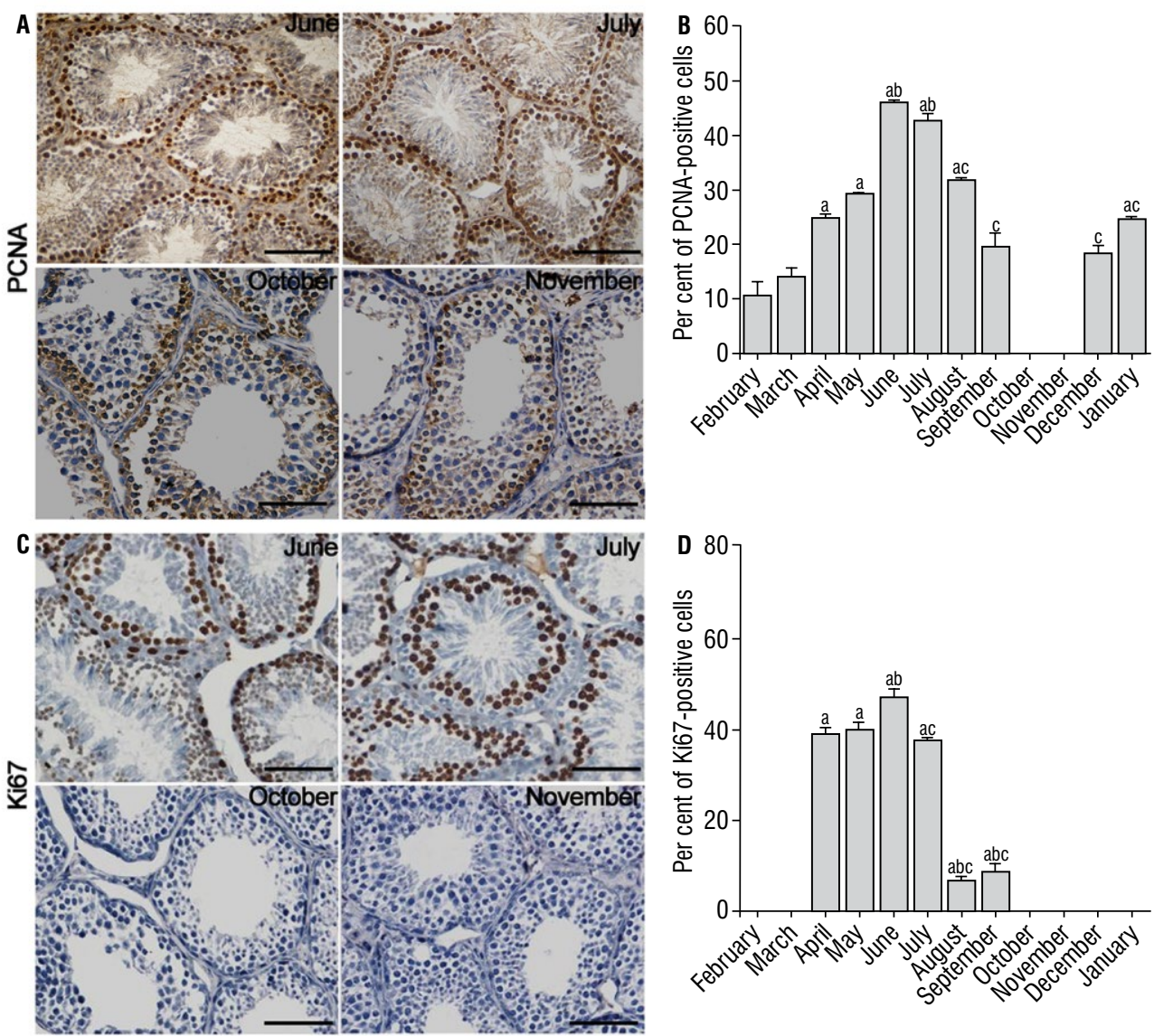

Figure 3. Immunostaining of proliferating cell nuclear antigen (PCNA) and Ki67 in the tree shrew testis; A. In June and July, in the spermatogenically active seminiferous epithelium, the nucleus of spermatogonia and primary spermatocytes had strong staining of PCNA with constant intensity. In October and November, the cytoplasm of spermatogonia and primary spermatocytes but not the nucleus is PCNA positive-staining; B. The rate of PCNA-positive cells of testis during the year (mean \pm standard deviation); C. In June and July, Ki67 expressed in spermatogonia, primary spermatocytes, and spermatids. In October and November, Ki67-positive cells were not detected in any spermatogenic cells in the seminiferous tubules of the tree shrews testis; $\mathbf{D}$. The rate of Ki67-postive cells of testis during the year (mean \pm standard deviation); bar $=100 \mu \mathrm{m}$; ${ }^{a} \mathrm{p}<0.05$ vs. February; ${ }^{\mathrm{b}} \mathrm{p}<0.05$ vs. April; ${ }^{\mathrm{c} p}<0.05$ vs. June.

4M). No apoptotic spermatogenic cells were observed in the testes in October and November (Fig. 4J, K).

\section{DISCUSSION}

To our knowledge, this is the first study showing the seasonal changes that occur in spermatids morphology and ultrastructural parameters in artificial tree shrews. We found seasonal differences in the microstructure of spermatids in domesticated tree shrews that were evident mainly at the late stage of spermatogenesis (i.e. the spermatids deformation stage).

From the perspective of sperm structure, sperm with abnormal morphologies were observed in the seminiferous tubules of domesticated tree shrew testes in months $1-5$ and 8-12. Some sperm abnor- malities can occur in the sperm head, such as head vacuolization and acrosome loss, while others can occur in the neck, body, or tail, such as tail crookedness and tail fracture. Studies have shown that sperm abnormalities often lead to declines in fertilisation potential $[2,18]$. Sperm motility and sperm deformity are negatively correlated, and deformities in different parts of sperm have different effects on sperm motility and egg fertilisation ability $[6,20]$. No abnormal sperm appeared from June to July. The findings indicate that the period from June to July is the period with the most orderly spermatogenesis in domesticated tree shrews, while the period from October to November is a period of relative stagnation. In wild tree shrews, Cao [4] found that highly active seminiferous epitheliums and typical cell associations in 

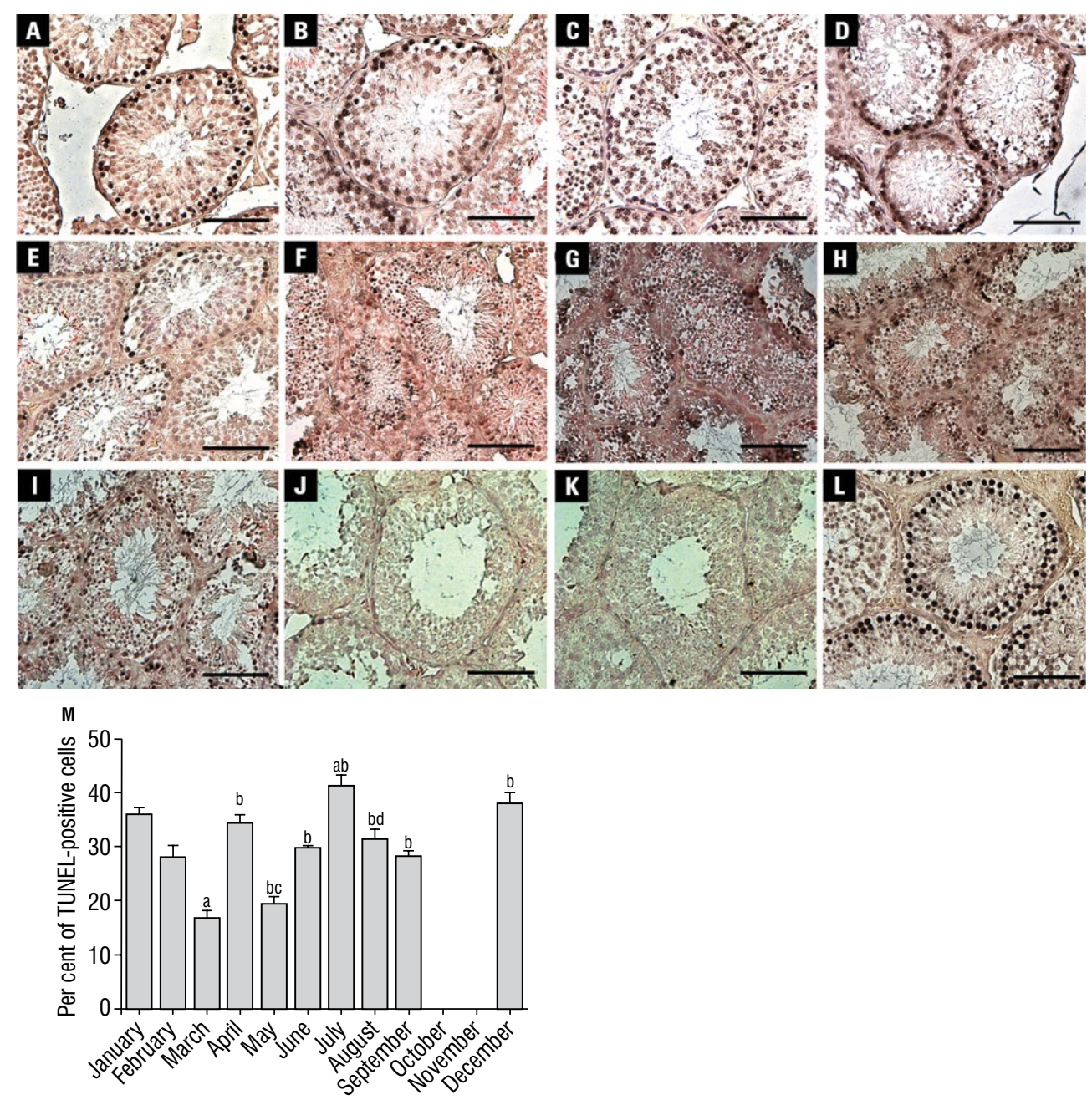

Figure 4. Apoptosis determined using terminal deoxynucleotidyl transferase dUTP nick end labelling (TUNEL) staining of seminiferous tubules of tree shrew; A-L. TUNEL staining of paraffin-embedded sections of testes from male tree shrew from January to December. Spontaneous apoptosis of germ cells appears in June and July with intensely stained spermatogonia and spermatocyte. No TUNEL-positive germ cells are observed in the testis of tree shrew from October and November; $\mathbf{M}$. The rate of TUNEL-positive male germ cells per seminiferous tubule. Values are presented as mean \pm standard deviation; bar $=100 \mu \mathrm{m}$; ${ }^{a} p<0.05$ vs. February; ${ }^{b} p<0.05$ vs. March; ${ }^{c} p<0.05$ vs. April; ${ }^{d p}<0.05$ vs. June.

January and April. Regression of seminiferous tubules begins in July, and extensive regressive changes in seminiferous epitheliums losing spermatogenic function in August and October. Similar seasonal changes in spermatozoa amount are shown in epididymis [4]. Our data are slightly different from previous results $[4,16]$. HE and TEM showed that the spermatogenesis cycle of domesticated tree shrews start later, with more vigorous spermatogenesis activity from June to July and the lowest in winter. This may be due to differences in living environment and female social stimulation. It is reported that captivity could alter activities of the neuroendocrine system, thereby control the reproduction [7].

We further assessed the protein levels of proliferation markers to determine the activation status of germ cells. PCNA is expressed only in proliferating cells and its levels peak in the $S$ phase of the cell cycle. Therefore, it is an important indicator for evaluation of cell proliferation [26]. Our IHC results showed that in June and July, PCNA was expressed in the nuclei of spermatogonia and primary spermatocytes in testicular tissue, suggesting that the spermatogenic cells were actively proliferating. The reason may be that the spermatogonia needed to undergo mitosis, as DNA replication occurs in $\mathrm{S}$ phase and also before meiosis in primary spermatocytes [28]. Interestingly, cytoplasmic PCNA staining was observed in October and November. Possibly, cytoplasmic PCNA localisation in tree shrew testis could be connected to a role of PCNA in apoptosis. This correlation pattern may be similar to that of humans, 
which is important for survival of human neutrophils and $\mathrm{HL}-60$ cells $[5,19]$. The Ki67 protein was mainly expressed in spermatogonia, primary spermatocytes and spermatids. Higher expression intensity was observed in spermatogonia and primary spermatocytes than in other types of cells. In the M phase of spermatogonial mitosis, the Ki67 protein functions in organizing and binding DNA and participates in the disappearance and reconstruction of nucleoli $[15,25]$. In addition, Ki67 protein was weakly expressed in secondary spermatocytes. We speculate that Ki67 protein expressed in spermatogonia and primary spermatocytes may not be completely degraded by the secondary spermatocyte and spermatid stages such that weak expression is still observed in these stages. From October to March, there is no immunostaining of spermatogenic cells with the Ki67 antibody in the testis. These are in accordance with the fact that the Ki67 protein immediately degrade after mitosis and that cell nuclei are generally Ki67 immunonegative during early G1- and G0-phase of the cell cycle [27].

Spontaneous apoptosis affects germ cell development. Therefore, in seasonally breeding animals, apoptosis may lead to changes in spermatogenesis [11]. In this study, the TUNEL results showed that apoptosis of spermatogonia, primary spermatocytes and small numbers of secondary spermatocytes and round spermatids occurred in the testicular tissue from January to September and December. Additionally, the TEM results showed that shell-shaped nucleoli were occasionally observed in primary spermatocytes in January and February. Since the nucleolus is where ribosomal RNA transcription and transformation take place, the proliferative activity of spermatogenic cells is reduced when the nucleolus becomes shell-shaped [21]. We further used the TUNEL method to examine the numbers, percentages and locations of apoptotic germ cells in seminiferous tubules in testicular sections. During the process of spermatogenesis (except October and November), TUNEL-positive germ cells were observed in seminiferous tubule from each month. Notably, the ratio of TUNEL-positive germ cells to total male germ cells is higher during active periods (July) than during other stages of spermatogenesis. Spermatogenesis is a very unique process involving not only the frequent division, proliferation and developmental differentiation of spermatogenic cells but also the continuous degradation of spermatogenic cells. The degeneration process of spermatogenic cells is mainly achieved through apoptosis $[10,12]$.
Apoptosis, a programmed cell death pathway, can eliminate damaged cells and cells with chromosomal abnormalities caused by meiotic or mitotic errors during the period when the proliferation rate of germ cells is elevated to ensure a sufficient number and quality of viable spermatogenic cells [1]. In addition, apoptosis may remove cells with PCNA-positive nuclei (such as spermatogonia and primary spermatocytes), thereby controlling the number of germ cells in the testes to respond to seasonal changes [17].

\section{CONCLUSIONS}

In this study, we showed seasonal differences in spermatogenesis in domesticated tree shrews, active in June and July, inactive in October and November. Apoptosis of spermatogonia and primary spermatocytes were observed, but may not contribute to the germ-cell loss; sperm cells restored by cell proliferation in the next reproductive cycle.

\section{Acknowledgements}

The authors thank Associate Professor Jingling Song from the Electron Microscopy Centre of Kunming Medical University for her help in testicular electron microscopy.

\section{Funding}

This study was supported by grants from The Applied Basic Research Foundation of Yunnan Province Science and Technology Department and Kunming Medical University [No. 2018FE001(-187)].

Conflict of interest: None declared

\section{REFERENCES}

1. Aitken RJ, Findlay JK, Hutt KJ, et al. Apoptosis in the germ line. Reproduction. 2011; 141(2): 139-150, doi: 10.1530/ REP-10-0232, indexed in Pubmed: 21148286.

2. Ben-Rafael Z, Farhi J, Feldberg D, et al. Follicle-stimulating hormone treatment for men with idiopathic oligoteratoasthenozoospermia before in vitro fertilization: the impact on sperm microstructure and fertilization potential. Fertil Steril. 2000; 73(1): 24-30, doi: 10.1016/ s0015-0282(99)00461-6, indexed in Pubmed: 10632407.

3. Blottner S, Hingst $\mathrm{O}$, Meyer $\mathrm{HH}$. Inverse relationship between testicular proliferation and apoptosis in mammalian seasonal breeders. Theriogenology. 1995; 44(3): 321-328, doi: 10.1016/0093-691x(95)00187-d, indexed in Pubmed: 16727732.

4. Cao XM. Seasonal changes in spermatogenesis of tree shrew (Tupaia belangeri Chinensis). Zool Res. 1989; 10(1): 15-21.

5. De Chiara A, Pederzoli-Ribeil M, Burgel PR, et al. Targeting cytosolic proliferating cell nuclear antigen in neutro- 
phil-dominated inflammation. Front Immunol. 2012; 3: 311, doi: 10.3389/fimmu.2012.00311, indexed in Pubmed: 23181059.

6. Donnelly ET, Lewis SE, McNally JA, et al. In vitro fertilization and pregnancy rates: the influence of sperm motility and morphology on IVF outcome. Fertil Steril. 1998; 70(2): 305-314, doi: 10.1016/s0015-0282(98)00146-0, indexed in Pubmed: 9696226.

7. DuRant S, Love AC, Belin B, et al. Captivity alters neuroendocrine regulators of stress and reproduction in the hypothalamus in response to acute stress. Gen Comp Endocrinol. 2020; 295: 113519, doi: 10.1016/j. ygcen.2020.113519, indexed in Pubmed: 32470473.

8. Fan Yu, Huang ZY, Cao CC, et al. Genome of the Chinese tree shrew. Nat Commun. 2013; 4: 1426, doi: 10.1038/ ncomms2416, indexed in Pubmed: 23385571.

9. França LR, Avelar GF, Almeida FFL. Spermatogenesis and sperm transit through the epididymis in mammals with emphasis on pigs. Theriogenology. 2005; 63(2): 300-318, doi: 10.1016/j.theriogenology.2004.09.014, indexed in Pubmed: 15626401.

10. Hsueh AJ, Eisenhauer K, Chun SY, et al. Gonadal cell apoptosis. Recent Prog Horm Res. 1996; 51: 433-55; discussion 455, indexed in Pubmed: 8701090.

11. Ito J, Meguro K, Komatsu K, et al. Seasonal changes in the spermatogenesis of the large Japanese field mice (Apodemus speciosus) controlled by proliferation and apoptosis of germ cells. Anim Reprod Sci. 2020; 214: 106288, doi: 10.1016/j.anireprosci.2020.106288, indexed in Pubmed: 32087913.

12. Jahnukainen K, Chrysis D, Hou Mi, et al. Increased apoptosis occurring during the first wave of spermatogenesis is stage-specific and primarily affects midpachytene spermatocytes in the rat testis. Biol Reprod. 2004; 70(2): 290-296, doi: 10.1095/biolreprod.103.018390, indexed in Pubmed: 14522836.

13. Korgun ET, Celik-Ozenci C, Acar N, et al. Location of cell cycle regulators cyclin B1, cyclin A, PCNA, Ki67 and cell cycle inhibitors p21, p27 and p57 in human first trimester placenta and deciduas. Histochem Cell Biol. 2006; 125(6): 615-624, doi: 10.1007/s00418-006-0160-y, indexed in Pubmed: 16491347.

14. Li B, Chen LI, Liu RW, et al. Preliminary discussions about laboratory breeding and management of tupaia belangeri chinensis. Sci Tech Info. 2008; 2008(35): 664.

15. Liberal V, De Miguel MP, Henze M, et al. Reduced spermatogonial proliferation and decreased fertility in mice overexpressing cyclin E in spermatogonia. Cell Cycle. 2010; 9(20): 4222-4227, doi: 10.4161/cc.9.20.13544, indexed in Pubmed: 20962587.

16. Maeda S, Endo H, Kimura J, et al. Classification of the cycle of the seminiferous epithelium in the common tree shrew (Tupaia glis). J Vet Med Sci. 1996; 58(5): 481-484, doi: 10.1292/jvms.58.481, indexed in Pubmed: 8741615.

17. Müller R, Misund $K$, Holien T, et al. Targeting proliferating cell nuclear antigen and its protein interactions induces apoptosis in multiple myeloma cells. PLoS One. 2013; 8(7): e70430, doi: 10.1371/journal.pone.0070430, indexed in Pubmed: 23936203.

18. Nikolettos N, Küpker W, Demirel $C$, et al. Fertilization potential of spermatozoa with abnormal morphology.
Hum Reprod. 1999; 14 Suppl 1: 47-70, doi: 10.1093/ humrep/14.suppl_1.47, indexed in Pubmed: 10573024.

19. Ohayon D, De Chiara A, Chapuis N, et al. Cytoplasmic proliferating cell nuclear antigen connects glycolysis and cell survival in acute myeloid leukemia. Sci Rep. 2016; 6: 35561, doi: 10.1038/srep35561, indexed in Pubmed: 27759041.

20. Pereira R, Sá R, Barros $A$, et al. Major regulatory mechanisms involved in sperm motility. Asian J Androl. 2017; 19(1): 5-14, doi: 10.4103/1008-682X.167716, indexed in Pubmed: 26680031.

21. Romano FJ, Rossetti S, Conteduca V, et al. Role of DNA repair machinery and p53 in the testicular germ cell cancer: a review. Oncotarget. 2016; 7(51): 85641-85649, doi: 10.18632/ oncotarget.13063, indexed in Pubmed: 27821802.

22. Sanada T, Tsukiyama-Kohara K, Shin-I T, et al. Construction of complete Tupaia belangeri transcriptome database by whole-genome and comprehensive RNA sequencing. Sci Rep. 2019; 9(1): 12372, doi: 10.1038/s41598-01948867-x, indexed in Pubmed: 31451757.

23. Scholzen T, Gerdes J. The Ki-67 protein: from the known and the unknown. J Cell Physiol. 2000; 182(3): 311-322, doi: 10.1002/(SICI)1097-4652(200003)182:3<311::AIDJCP1 > 3.0.CO;2-9, indexed in Pubmed: 10653597.

24. Shen P-Q, Zheng H, Liu RW. Progress and prospect in research on laboratory tree shrew in China. Dongwuxue Yanjiu. 2011; 32(1): 109-114, doi: 10.3724/SP.J.1141.2011.01109, indexed in Pubmed: 21341393.

25. Steger K, Aleithe I, Behre $\mathrm{H}$, et al. The proliferation of spermatogonia in normal and pathological human seminiferous epithelium: an immunohistochemical study using monoclonal antibodies against Ki-67 protein and proliferating cell nuclear antigen. Mol Hum Reprod. 1998; 4(3): 227-233, doi: 10.1093/molehr/4.3.227, indexed in Pubmed: 9570268.

26. Strzalka W, Ziemienowicz A. Proliferating cell nuclear antigen (PCNA): a key factor in DNA replication and cell cycle regulation. Ann Bot. 2011; 107(7): 1127-1140, doi: 10.1093/aob/mcq243, indexed in Pubmed: 21169293.

27. Sun X, Kaufman PD. Ki-67: more than a proliferation marker. Chromosoma. 2018; 127(2): 175-186, doi: 10.1007/ s00412-018-0659-8, indexed in Pubmed: 29322240.

28. White-Cooper H, Doggett K, Ellis R. The evolution of spermatogenesis. Sperm Biology. 2009: 151-183, doi: 10.1016/b978-0-12-372568-4.00004-5.

29. Xiao-mei C. Seasonal changes in spermatogenesis of tree shrew (Tupaia belangeri Chinensis). Zool Res. 1989; 10(1): 15-21.

30. Yao YG. Creating animal models, why not use the Chinese tree shrew (Tupaia belangeri chinensis)? Zool Res. 2017; 38(3): 118.

31. Zhao WP, Wang HW, Liu J, et al. Positive PCNA and Ki-67 expression in the testis correlates with spermatogenesis dysfunction in fluoride-treated rats. Biol Trace Elem Res. 2018; 186(2): 489-497, doi: 10.1007/s12011-018-1338-6, indexed in Pubmed: 29748930.

32. Zhong S, Zhang Sy, Xing Hj, et al. Revealing histological and morphological features of female reproductive system in tree shrew (Tupaia belangeri). Zoomorphology. 2017; 137(1): 191-199, doi: 10.1007/s00435-017-0374-7. 